\title{
Effect of apolipoprotein C3 genetic polymorphisms on serum lipid levels and the risk of intracerebral hemorrhage
}

Yan Jiang, Junpeng Ma, Hao Li, Yi Liu and Chao You*

\begin{abstract}
Background: Serum lipid levels are associated with the risk of intracerebral hemorrhage (ICH). Genetic variants in the apolipoprotein C3 (APOC3) gene were associated with plasma triglyceride (TG) and very-low-density lipoprotein (VLDL) levels. The aim of this study was to evaluate the effect of two genetic variants (1100 C/T and $3238 \mathrm{C} / \mathrm{G}$ ) of APOC3 on serum lipid levels and risk of $\mathrm{ICH}$.

Methods: A prospective hospital-based case-control design and logistic regression analysis were utilized. We enrolled $150 \mathrm{ICH}$ patients and 150 age- and gender-matched controls. The APOC3 gene polymorphisms were determined by polymerase chain reaction-restriction fragment length polymorphism (PCR-RFLP).
\end{abstract}

Results: ICH patients had a significantly higher frequency of APOC3 $3238 \mathrm{GG}$ genotype [odds ratio $(\mathrm{OR})=2.97,95 \%$ confidence interval $(C l)=1.20,7.38 ; P=0.02]$ and $A P O C 33238 \mathrm{G}$ allele $(\mathrm{OR}=1.53,95 \% \mathrm{Cl}=1.03,2.27 ; P=0.04)$ than controls. The APOC3 $3238 \mathrm{G}$ allele was significantly associated with increasing plasma TG levels and VLDL levels both in ICH cases $(P=0.01)$ and controls $(P=0.02)$. No association was found between APOC3 $1100 \mathrm{C} / \mathrm{T}$ polymorphisms and $\mathrm{ICH}$.

Conclusion: To the best of our knowledge, this is the first report in the literature that the APOC3 3238 GG genotype and $\mathrm{G}$ allele might contribute to an increased risk of $\mathrm{ICH}$ as a result of its effect on serum lipid levels.

Keywords: Intracerebral hemorrhage, Lipid, Apolipoprotein C3, Gene polymorphism

\section{Introduction}

Intracerebral hemorrhage ( $\mathrm{ICH})$ occurs at an annual incidence rate of 15 to 19 per 100,000 [1]. ICH accounts for about $15 \%$ of all strokes and is associated with 3month mortality of approximately $25 \%$ [1,2]. Even with state-of-the-art medical care, ICH results in death, or severe disability in more than $50 \%$ of cases $[3,4]$. ICH may occur due to hypertension, diabetes mellitus, vascular malformation, menopause, cerebral amyloid angiopathy, current cigarette smoking, trauma, coagulopathy [5-9], and serum lipid levels [10-12].

Apolipoprotein C3 (APOC3) is a major component of triglyceride (TG)-rich lipoproteins, and a minor component of high-density lipoprotein (HDL) [13]. APOC3 gene,

\footnotetext{
* Correspondence: cyouwch@outlook.com

Department of Neurosurgery, West China Hospital, Sichuan University,

37 Guoxuexiang Street, Chengdu 610041, China
}

located in the chromosome 11q23, was involved in transport, and clearance of chylomicron remnants, and very-low-density lipoprotein (VLDL), and HDL from the bloodstream [14, 15]. APOC3 encodes a 79-amino-acid glycoprotein produced mainly in the liver inhibiting the action of lipoprotein lipase and interfering with receptormediated lipoprotein uptake [16]. Two common single nucleotide polymorphisms (SNPs) have been identified in the APOC3 gene: $1100 \mathrm{C} / \mathrm{T}$ and $3238 \mathrm{C} / \mathrm{G}[17,18]$. Genetic variants in the $A P O C 3$ gene were associated with plasma TG and VLDL levels [19, 20].

We hypothesized that common genetic variants in APOC3 gene influenced the risk of ICH. To test this hypothesis, we performed a prospective hospital-based casecontrol study to evaluate the effect of two genetic variants $(1100 \mathrm{C} / \mathrm{T}$ and $3238 \mathrm{C} / \mathrm{G})$ of $A P O C 3$ on serum lipid levels and risk of $\mathrm{ICH}$. 


\section{Materials and methods Study population}

This is a prospective hospital-based case-control study between July 2011 and July 2013 in the Department of Neurosurgery, West China Hospital, Sichuan University, China. We enrolled $150 \mathrm{ICH}$ patients and 150 age- and gender-matched controls. Eligibility for $\mathrm{ICH}$ patients required neuroimaging (CT or MRI) confirmation of hemorrhagic stroke. Exclusion criteria were defined as: presence of a vascular malformation, aneurysmal subarachnoid hemorrhage, hemorrhagic transformation of acute infarction, traumatic $\mathrm{ICH}$, brain neoplasm, or any other suspected cause of secondary $\mathrm{ICH}$. Controls were confirmed to have no medical history of $\mathrm{ICH}$, Alzheimer's disease, or pre-enrollment dementia by means of interview and review of medical records. In addition, similar to the cases the controls were all required to be born in China to native Chinese Han parents. To confirm the diagnosis, two physicians reviewed the hospital records and validated each case. Collected clinical data included age, sex, body mass index (BMI), smoking status, and medical history including hypertension, diabetes mellitus, hyperlipidemia, ischemic stroke, and previous ICH. Medications included the use of warfarin, antiplatelet therapy, and statins. All data points were collected through interviews with the patient or their families/surrogates. All parts of the study were approved by the Institutional Ethical Committee of the West China Hospital, Sichuan University, and informed consent according to the Declaration of Helsinki was obtained from all participants or their families/surrogates.

\section{DNA extraction and genotyping}

Genomic DNA was isolated from white blood cells by the commercially available Qiagen kit (QIAGEN Inc., Valencia, CA, USA). The APOC3 gene polymorphisms were determined by polymerase chain reaction-restriction fragment length polymorphism (PCR-RFLP). Briefly, the primers designed for APOC3 $1100 \mathrm{C} / \mathrm{T}$ and $3238 \mathrm{C} / \mathrm{G}$ were 5'-AGA GGC CGA TCC ACC CCA CTC AGC C3' (forward) and 5'-GGC GGT CTT GGT GGC GTG CTT CAG G-3' (reverse); 5'-CAT GGT TGC CTA CAG AGG AGT-3' (forward) and 5'-TGA CCT TCC GCA CAA AGC TGT-3' (reverse), respectively. The amplified PCR products were digested with SstI $(3238 \mathrm{C} / \mathrm{G})$ and SacI (1100 C/T) (New England BioLabs, Missisauga, ON). Details of PCR conditions have been described elsewhere [21]. Electrophoresis in a $2.5 \%$ agarose gel followed by ethidium bromide staining and ultraviolet illumination allowed detection of the alleles. For quality control, two independent observers, read all genotypes without knowing about the case or control status. When replicate quality control samples were evaluated, genotypes showed $100 \%$ concordance.

\section{Biochemical analysis}

Serum total cholesterol (TC), triglycerides (TG), highdensity lipoprotein cholesterol (HDL-C) were measured by the clinical chemistry department using commercial kits following the manufacturer instructions. Commercial kits for measuring TC, TG, HDL-C, and LDL-C were obtained from Beijing BHKT Clinical Reagent Co., Ltd. (Beijing, China). All of the serum samples were measured with a SpectraMax M2 microplate reader (Molecular Devices, USA). Serum low-density lipoprotein cholesterol (LDL-C) and very-low-density lipoprotein cholesterol (VLDL-C) were calculated using the Friedwald's formula. The immunoturbidimetric assay (BioSino Biotechnology and Science Inc., Beijing, China) was used to quantify the plasma concentrations of ApoA1 and ApoB. All assays were conducted following the manufactures' instruction.

\section{Statistical analysis}

SAS version 9.1 (SAS Institute, Cary, NC) was used for all statistical tests. Data are presented as means \pm standard deviation (SD) or as percentages for categorical variables. Differences between continuous variables were assessed by Student's $t$ test, while those between categorical variables were evaluated using Pearson $x^{2}$ test. To eliminate confounding influences, a binary logistic-regression model was used to determine ICH risk (estimated by the odds ratio [OR] with $95 \%$ confidence interval [95 \% CI]) by adjustment for conventional risk factors, including age, sex, BMI, smoking status, history of hypertension, or diabetes,

Table 1 General characteristics of ICH patients and controls

\begin{tabular}{llll}
\hline Variables & $\mathrm{ICH}$ & Controls & $P$ \\
\hline Number of subjects & 150 & 150 & \\
Age (years), (mean $\pm \mathrm{SD})$ & $65.3 \pm 11.2$ & $64.8 \pm 10.9$ & 0.69 \\
Sex (Male/Female) & $89 / 61$ & $92 / 58$ & 0.72 \\
BMI (Kg/m ${ }^{2}$ ) & $25.7 \pm 3.3$ & $25.3 \pm 3.2$ & 0.29 \\
Smoking status (Ever/Never) & $31 / 119$ & $17 / 133$ & 0.03 \\
Hypertension (Positive/Negative) & $91 / 59$ & $43 / 107$ & $<0.001$ \\
Diabetes (Positive/Negative) & $35 / 115$ & $14 / 136$ & 0.001 \\
Hyperlipidemia (Positive/Negative) & $43 / 107$ & $22 / 128$ & 0.004 \\
TG (mg/dL) & $176.3 \pm 87.5$ & $149.8 \pm 75.6$ & 0.005 \\
TC (mg/dL) & $196.8 \pm 59.5$ & $178.4 \pm 51.4$ & 0.004 \\
HDL (mg/dL) & $34.5 \pm 15.6$ & $38.9 \pm 16.7$ & 0.02 \\
LDL (mg/dL) & $127.0 \pm 46.5$ & $109.5 \pm 43.7$ & 0.001 \\
VLDL (mg/dL) & $35.3 \pm 17.5$ & $30.0 \pm 15.1$ & 0.005 \\
ApoA1 (mg/dL) & $124.1 \pm 21.5$ & $122.7 \pm 21.8$ & 0.58 \\
ApoB (mg/dL) & $89.3 \pm 19.4$ & $88.5 \pm 19.2$ & 0.72 \\
\hline
\end{tabular}

ICH intracerebral hemorrhage, BMI body mass index, TG triglyceride, TC total cholesterol, $H D L$ high-density lipoprotein, $L D L$ low-density lipoprotein, VLDL very-low-density lipoprotein, Apo apolipoprotein 
Table 2 Genotype and allele frequencies of APOC3 gene polymorphisms among $\mathrm{ICH}$ cases and healthy controls

\begin{tabular}{lllll}
\hline Genotypes & $\mathrm{ICH}(\%)$ & Controls (\%) & OR $(95 \% \mathrm{Cl})$ & $P$ \\
\hline $1100 \mathrm{CC}$ & $58(38.7)$ & $63(42.0)$ & 1.00 (Reference) & \\
$1100 \mathrm{CT}$ & $65(43.3)$ & $53(35.3)$ & $1.33(0.80,2.22)$ & 0.27 \\
$1100 \mathrm{TT}$ & $27(18.0)$ & $34(22.7)$ & $0.86(0.47,1.60)$ & 0.64 \\
$1100 \mathrm{C}$ allele frequency & $181(60.3)$ & $179(59.7)$ & 1.00 (Reference) & \\
$1100 \mathrm{~T}$ allele frequency & $119(39.7)$ & $121(40.3)$ & $0.97(0.70,1.35)$ & 0.87 \\
$3238 \mathrm{CC}$ & $95(63.3)$ & $104(69.3)$ & 1.00 (Reference) & \\
$3238 \mathrm{CG}$ & $36(24.0)$ & $39(26.0)$ & $1.01(0.59,1.72)$ & 0.97 \\
$3238 \mathrm{GG}$ & $19(12.7)$ & $7(4.7)$ & $2.97(1.20,7.38)$ & 0.02 \\
$3238 \mathrm{C}$ allele frequency & $226(75.3)$ & $247(82.3)$ & $1.00($ Reference) & \\
$3238 \mathrm{G}$ allele frequency & $74(24.7)$ & $53(17.7)$ & $1.53(1.03,2.27)$ & 0.04 \\
\hline
\end{tabular}

Adjustment for conventional risk factors, including age, sex, BMI, smoking status, history of hypertension, or diabetes, total cholesterol, HDL-C, LDL-C, and medicine use by which lipid levels are affected

ICH intracerebral hemorrhage

total cholesterol, HDL-C, and LDL-C. We also have adjusted for medicine use by which lipid levels are affected in this analysis. The plasma lipid levels were compared among different genotypes by ANCOVA, adjusted for gender, age, and BMI. Statistical significance was taken at nominal $P$-value $<0.05$ for all comparisons.

\section{Results}

\section{Characteristics of participants}

General characteristics of ICH patients and controls were presented in Table 1 . There were no significant differences between the $\mathrm{ICH}$ patients and controls in age, sex, BMI, ApoA1, and ApoB (Table 1). The proportions of smoking status $(P=0.03)$, hypertension $(P<0.001)$, diabetes $(P=$ $0.001)$, and hyperlipidemia $(P=0.004)$ were significantly higher, and levels of TG $(P=0.005)$, TC $(P=0.004)$, LDL $(P=0.001)$ and VLDL $(P=0.005)$ were significantly higher, and levels of HDL were significantly lower $(P=0.02)$ in ICH patients than in controls (Table 1).

\section{APOC3 3238 C/G polymorphisms, serum lipid levels, and $\mathrm{ICH}$}

ICH patients had a significantly higher frequency of APOC3 3238 GG genotype $(\mathrm{OR}=2.97,95 \% \mathrm{CI}=1.20$, 7.38; $P=0.02)$ and $A P O C 33238 \mathrm{G}$ allele $(\mathrm{OR}=1.53$, $95 \% \mathrm{CI}=1.03,2.27 ; P=0.04$ ) than controls (Table 2). The APOC3 $3238 \mathrm{G}$ allele was significantly associated with increasing plasma TG levels and VLDL levels both in ICH cases $(P=0.01)$ and controls $(P=0.02)$ (Table 3$)$.

\section{APOC3 $1100 \mathrm{C} / \mathrm{T}$ polymorphisms, serum lipid levels, and $\mathrm{ICH}$ \\ No association was found between APOC3 $1100 \mathrm{C} / \mathrm{T}$ polymorphisms and ICH (Table 2).}

\section{Discussion}

In this study, we evaluated the effect of two genetic variants (1100 C/T and $3238 \mathrm{C} / \mathrm{G})$ of APOC3 on serum lipid levels and risk of $\mathrm{ICH}$ in a Chinese population. This prospective hospital-based case-control study revealed that the APOC3 3238 GG genotype and G allele might contribute to an increased risk of $\mathrm{ICH}$ as a result of its effect on serum lipid levels. No association was found between APOC3 $1100 \mathrm{C} / \mathrm{T}$ polymorphisms and ICH. To the best of our knowledge, this is the first report in the literature that evaluated the effect of two genetic variants $(1100 \mathrm{C} /$ $\mathrm{T}$ and $3238 \mathrm{C} / \mathrm{G}$ ) of $A P O C 3$ on serum lipid levels and risk of $\mathrm{ICH}$.

The APOC3 gene polymorphisms were also associated with many other diseases. A nested case-control study demonstrated a diet-gene interaction between APOC3 rs5128 polymorphism and the western dietary patterns in relation to metabolic syndrome risk [22]. Two other case-control study also suggested that two genetic variants $(-482 \mathrm{C} / \mathrm{T}$ and $-455 \mathrm{~T} / \mathrm{C})$ of $A P O C 3$ were associated with the metabolic syndrome [23, 24]. The GENOCOR study identified $-482 \mathrm{C}>\mathrm{T}$ of $A P O C 3$ as an additive biomarker for ischemic heart disease in an Italian cohort of ischemic patients [25]. A systematic review of 20 studies

Table 3 Lipid profiles of ICH cases and controls according to APOC3 3238 C/G polymorphisms

\begin{tabular}{|c|c|c|c|c|c|c|c|c|}
\hline & \multicolumn{3}{|l|}{$\mathrm{ICH}$} & \multirow[t]{2}{*}{$P$ value } & \multicolumn{3}{|l|}{ Controls } & \multirow[t]{2}{*}{$P$ value } \\
\hline & $\mathrm{CC}$ & $C G$ & GG & & $C C$ & $C G$ & GG & \\
\hline $\mathrm{TG}(\mathrm{mg} / \mathrm{dL})$ & $159.7 \pm 85.3$ & $196.3 \pm 92.1$ & $236.7 \pm 103.4$ & 0.01 & $131.5 \pm 68.7$ & $173.4 \pm 79.8$ & $219.5 \pm 89.6$ & 0.02 \\
\hline TC (mg/dL) & $192.1 \pm 59.1$ & $208.5 \pm 60.8$ & $198.8 \pm 59.8$ & 0.58 & $174.6 \pm 51.0$ & $191.5 \pm 58.7$ & $161.8 \pm 44.9$ & 0.83 \\
\hline $\mathrm{HDL}(\mathrm{mg} / \mathrm{dL})$ & $33.7 \pm 17.6$ & $38.2 \pm 18.3$ & $31.5 \pm 9.8$ & 0.74 & $35.8 \pm 15.1$ & $42.4 \pm 19.6$ & $35.4 \pm 14.8$ & 0.54 \\
\hline LDL (mg/dL) & $126.5 \pm 45.7$ & $131.0 \pm 48.2$ & $120.1 \pm 41.6$ & 0.63 & $110.5 \pm 38.1$ & $114.4 \pm 38.5$ & $82.5 \pm 33.8$ & 0.41 \\
\hline VLDL (mg/dL) & $31.9 \pm 17.1$ & $39.3 \pm 18.4$ & $47.3 \pm 20.7$ & 0.01 & $26.3 \pm 13.7$ & $34.7 \pm 16.0$ & $43.9 \pm 17.9$ & 0.02 \\
\hline ApoA1 (mg/dL) & $122.5 \pm 22.9$ & $127.3 \pm 24.5$ & $126.1 \pm 23.4$ & 0.26 & $119.3 \pm 20.6$ & $132.1 \pm 26.7$ & $120.6 \pm 21.5$ & 0.37 \\
\hline ApoB (mg/dL) & $87.2 \pm 18.7$ & $96.2 \pm 21.6$ & $86.7 \pm 18.1$ & 0.46 & $85.1 \pm 17.7$ & $98.0 \pm 22.4$ & $86.1 \pm 18.2$ & 0.51 \\
\hline
\end{tabular}

$P$ values were calculated by ANCOVA, adjusted for age, sex, and BMI 
comprising 15,591 participants found that APOC3 Sst I and T-455C polymorphisms might be associated with coronary heart disease risk [17]. A case-control study suggested that the APOC3 $3238 \mathrm{G}$ allele might contribute to an increased risk of coronary artery disease as a result of its effect on TG and VLDL-C metabolism [26]. A casecontrol study found that the minor alleles of $A P O C 3$ $-455 \mathrm{~T} / \mathrm{C}$ polymorphisms were closely associated with acute coronary syndrome [27]. A prospective case-control study suggested that $A P O C 3(-455 \mathrm{~T}>\mathrm{C})$ genetic variation was involved in the susceptibility to developing nonalcoholic fatty liver disease, insulin resistance, hypertension, hypertriglyceridemia, and low HDL in the Southern Chinese Han population [28]. Another case-control study found that the polymorphisms $-482 \mathrm{C} / \mathrm{T}$ and $-455 \mathrm{~T} / \mathrm{C}$ in $\mathrm{APOC} 3$ were associated with nonalcoholic fatty liver disease and insulin resistance [29].

Although our study suggested that the APOC3 GG genotype and $\mathrm{G}$ allele might contribute to an increased risk of $\mathrm{ICH}$ as a result of its effect on serum lipid levels, the clear mechanism of this association is unclear. The Bogalusa Heart Study found that APOC3 3238 C/G polymorphisms were associated with higher serum triglyceride levels [30]. A recent prospective case-control study also found that the APOC3 $3238 \mathrm{G}$ allele might contribute to an increased risk of coronary artery disease as a result of its effect on TG and VLDL-C metabolism [26]. Serum lipid levels may be associated with the risk of ICH [10-12]. We also observed that the proportions of smoking status, hypertension, diabetes, and hyperlipidemia were significantly higher, and levels of TG, TC, LDL, and VLDL were significantly higher, and levels of HDL were significantly lower in ICH patients than in controls.

Some shortcomings of this study should be mentioned. First of all, this study is limited by its size and lack of replication. Further large scale research on the role of $A P O C 3$ in $\mathrm{ICH}$ and replication of our results is necessary. Second, although we have adjusted for medicine use by which lipid levels are affected in this analysis, no information could be received on the baseline lipid levels of these patients. Third, this study only considers a Chinese population that may limit the application of these findings to other ethnic populations. Fourth, ICH is induced by multiple genes and environmental factors, which were not explored in the present study. Finally, potential selection bias might have been present, because this is a hospital based case control study and the subjects may not be representative of the general population.

\section{Conclusion}

To the best of our knowledge, this is the first report in the literature that the APOC3 3238 GG genotype and G allele might contribute to an increased risk of $\mathrm{ICH}$ as a result of its effect on serum lipid levels. We found that $\mathrm{ICH}$ patients had a significantly higher frequency of APOC3 3238 GG genotype and APOC3 $3238 \mathrm{G}$ allele than controls. The APOC3 $3238 \mathrm{G}$ allele was significantly associated with increasing plasma TG levels and VLDL levels both in ICH cases and controls. No association was found between $A P O C 31100 \mathrm{C} / \mathrm{T}$ polymorphisms and $\mathrm{ICH}$. Additional large scale studies are needed to confirm this finding.

\section{Competing interest}

The authors declare that they have no competing interests.

\section{Authors' contributions}

YJ and CY carried out the molecular genetic studies and drafted the manuscript. JM carried out the genotyping. $\mathrm{HL}$ and $\mathrm{YL}$ participated in the design of the study and performed the statistical analysis. YJ, JM, HL, YL, and CY conceived of the study, and participated in its design and coordination and helped to draft the manuscript. All authors read and approved the final manuscript.

\section{Acknowledgements}

Thanks are expressed to all coinvestigators, local project coordinators, research assistants, laboratory technicians, and secretaries/administrative assistants.

Received: 14 January 2015 Accepted: 14 May 2015

Published online: 22 May 2015

\section{References}

1. van Asch CJ, Luitse MJ, Rinkel GJ, van der Tweel I, Algra A, Klijn CJ. Incidence, case fatality, and functional outcome of intracerebral haemorrhage over time, according to age, sex, and ethnic origin: a systematic review and meta-analysis. Lancet Neurol. 2010;9:167-76.

2. Qureshi Al, Tuhrim S, Broderick JP, Batjer HH, Hondo H, Hanley DF. Spontaneous intracerebral hemorrhage. N Engl J Med. 2001;344:1450-60.

3. Broderick J, Connolly S, Feldmann E, Hanley D, Kase C, Krieger D, et al. Guidelines for the management of spontaneous intracerebral hemorrhage in adults: 2007 update: a guideline from the American Heart Association/ American stroke association stroke council, high blood pressure research council, and the quality of care and outcomes in research interdisciplinary working group. Stroke. 2007;38:2001-23.

4. Rosand J, Eckman MH, Knudsen KA, Singer DE, Greenberg SM. The effect of warfarin and intensity of anticoagulation on outcome of intracerebral hemorrhage. Arch Intern Med. 2004;164:880-4.

5. Brott $T$, Thalinger $K$, Hertzberg $V$. Hypertension as a risk factor for spontaneous intracerebral hemorrhage. Stroke. 1986;17:1078-83.

6. Mutoh T, Kobayashi S, Ishikawa T, Moroi J, Miyata H, Suzuki A, et al. Pathologically confirmed cryptic vascular malformation as a cause of convexity subarachnoid hemorrhage: case report. Neurosurgery. 2012;70:E1322-8. discussion E1328.

7. Mehndiratta P, Manjila S, Ostergard T, Eisele S, Cohen ML, Sila C, et al. Cerebral amyloid angiopathy-associated intracerebral hemorrhage: pathology and management. Neurosurg Focus. 2012;32, E7.

8. Powers WJ. Intracerebral hemorrhage and head trauma: common effects and common mechanisms of injury. Stroke. 2010:41:S107-10.

9. Takahashi H, Urano T, Nagai N, Takada Y, Takada A. Progressive expansion of hypertensive intracerebral hemorrhage by coagulopathy. Am J Hematol. 1998;59:110-4

10. Lei C, Lin S, Wu B, Li H, Liu M, You C. Lipid levels are regionally associated with cerebral microbleeds in patients with intracerebral hemorrhage. J Stroke Cerebrovasc Dis. 2014;23:1195-8.

11. Wieberdink RG, Poels MM, Vernooij MW, Koudstaal PJ, Hofman A, van der Lugt $A$, et al. Serum lipid levels and the risk of intracerebral hemorrhage: the Rotterdam study. Arterioscler Thromb Vasc Biol. 2011;31:2982-9.

12. Roquer J, Rodriguez Campello A, Gomis M, Ois A, Munteis E, Bohm P. Serum lipid levels and in-hospital mortality in patients with intracerebral hemorrhage. Neurology. 2005;65:1198-202. 
13. Aalto-Setala K, Weinstock PH, Bisgaier CL, Wu L, Smith JD, Breslow JL. Further characterization of the metabolic properties of triglyceride-rich lipoproteins from human and mouse apoC-III transgenic mice. J Lipid Res. 1996:37:1802-11.

14. Masebe T, Bessong PO, Ndip RN, Meyer D. Genetic variants of APOC3 promoter and HLA-B genes in an HIV infected cohort in northern South Africa: a pilot study. Int J Mol Sci. 2014;15:11403-15.

15. Tarr PE, Taffe $P$, Bleiber $G$, Furrer $H$, Rotger $M$, Martinez $R$, et al. Modeling the influence of $A P O C 3, A P O E$, and TNF polymorphisms on the risk of antiretroviral therapy-associated lipid disorders. J Infect Dis. 2005;191:1419-26.

16. Karathanasis SK. Apolipoprotein multigene family: tandem organization of human apolipoprotein Al, CIII, and AIV genes. Proc Natl Acad Sci U S A. 1985:82:6374-8

17. Lin B, Huang Y, Zhang M, Wang J, Wu Y. Association between apolipoprotein C3 Sst I, T-455C, C-482 T and C1100T polymorphisms and risk of coronary heart disease. BMJ Open. 2014;4, e004156.

18. Fiegenbaum M, de Andrade FM, Hutz MH. Association between plasma lipid parameters and APOC3 genotypes in Brazilian subjects: effect of gender, smoking and APOE genotypes. Clin Chim Acta. 2007;380:175-81.

19. Shoulders CC, Harry PJ, Lagrost L, White SE, Shah NF, North JD, et al. Variation at the apo Al/CIII/AIV gene complex is associated with elevated plasma levels of apo CIII. Atherosclerosis. 1991;87:239-47.

20. Timpson NJ, Walter K, Min JL, Tachmazidou I, Malerba G, Shin SY, et al. A rare variant in $\mathrm{APOC} 3$ is associated with plasma triglyceride and VLDL levels in Europeans. Nat Commun. 2014;5:4871.

21. Waterworth DM, Ribalta J, Nicaud V, Dallongeville J, Humphries SE, Talmud P. ApoCIII gene variants modulate postprandial response to both glucose and fat tolerance tests. Circulation. 1999:99:1872-7.

22. Hosseini-Esfahani F, Mirmiran P, Daneshpour MS, Mehrabi Y, Hedayati M, Zarkesh $\mathrm{M}$, et al. Western dietary pattern interaction with APOC3 polymorphism in the risk of metabolic syndrome: Tehran lipid and glucose study. J Nutrigenet Nutrigenomics. 2014;7:105-17.

23. Miller M, Rhyne J, Chen H, Beach V, Ericson R, Luthra K, et al. APOC3 promoter polymorphisms C-482 T and T-455C are associated with the metabolic syndrome. Arch Med Res. 2007:38:444-51.

24. Pollex RL, Ban MR, Young TK, Bjerregaard P, Anand SS, Yusuf S, et al. Association between the $-455 \mathrm{~T}>\mathrm{C}$ promoter polymorphism of the APOC3 gene and the metabolic syndrome in a multi-ethnic sample. BMC Med Genet. 2007:8:80.

25. Vecoli C, Adlerstein D, Shehi E, Bigazzi F, Sampietro T, Foffa I, et al. Genetic score based on high-risk genetic polymorphisms and early onset of ischemic heart disease in an Italian cohort of ischemic patients. Thromb Res. 2014;133:804-10

26. Cui F, Li K, Li Y, Zhang X, An C. Apolipoprotein C3 genetic polymorphisms are associated with lipids and coronary artery disease in a Chinese population. Lipids Health Dis. 2014;13:170.

27. Ding Y, Zhu MA, Wang ZX, Zhu J, Feng JB, Li DS. Associations of polymorphisms in the apolipoprotein APOA1-C3-A5 gene cluster with acute coronary syndrome. J Biomed Biotechnol. 2012;2012:509420.

28. Li MR, Zhang SH, Chao K, Liao XH, Yao JY, Chen MH, et al. Apolipoprotein C3 $(-455 \mathrm{~T}>\mathrm{C})$ polymorphism confers susceptibility to nonalcoholic fatty liver disease in the Southern Han Chinese population. World J Gastroenterol. 2014;20:14010-7.

29. Petersen KF, Dufour S, Hariri A, Nelson-Williams C, Foo JN, Zhang XM, et al. Apolipoprotein C3 gene variants in nonalcoholic fatty liver disease. N Engl J Med. 2010;362:1082-9.

30. Hallman DM, Srinivasan SR, Chen W, Boerwinkle E, Berenson GS. Longitudinal analysis of haplotypes and polymorphisms of the APOA5 and APOC3 genes associated with variation in serum triglyceride levels: the Bogalusa Heart Study. Metabolism. 2006;55:1574-81.

\section{Submit your next manuscript to BioMed Central and take full advantage of:}

- Convenient online submission

- Thorough peer review

- No space constraints or color figure charges

- Immediate publication on acceptance

- Inclusion in PubMed, CAS, Scopus and Google Scholar

- Research which is freely available for redistribution

Submit your manuscript at www.biomedcentral.com/submit 